\title{
Preparation, Characterization and Structure Trends for Graphite Intercalation Compounds Containing Pyrrolidinium Cations
}

Hanyang Zhang, ${ }^{\dagger}$ Yuanyuan $\mathrm{Wu},{ }^{\dagger}$ Weekit Sirisaksoontorn, ${ }^{\dagger}$ Vincent T. Remcho ${ }^{\dagger}$ and Michael M. Lerner*, ${ }^{*}$

${ }^{\dagger}$ Department of Chemistry, Oregon State University, Corvallis, Oregon 97331-4003, United States

Department of Chemistry and Centre of Excellence for Innovation in Chemistry, Faculty of Science, Kasetsart University, Chatuchak, Bangkok 1090o, Thailand 


\section{Section 1. Syntheses of pyrrolidinium bromide salts}

N-alkyl-N-methylpyrrolidinium Bromide

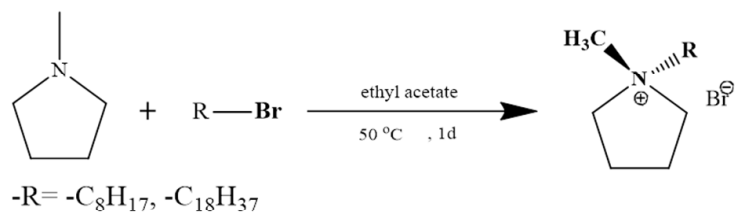

N-alkyl-N-butylpyrrolidinium Bromide

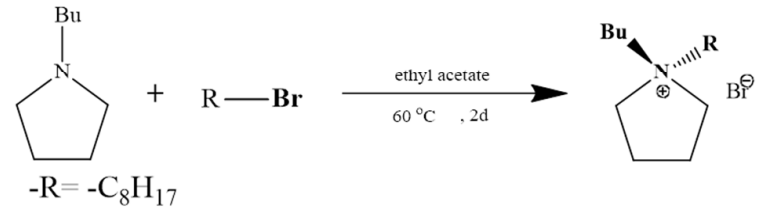

$N, N$-dialkylpyrrolidinium Bromide

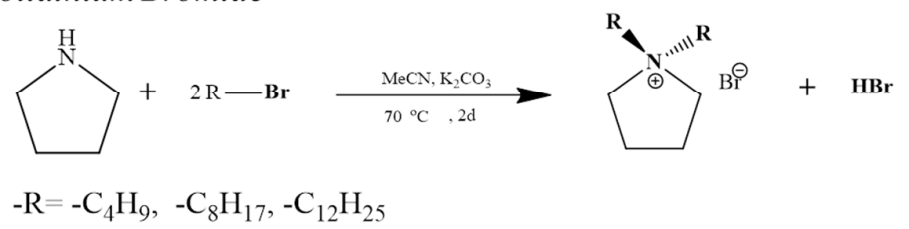

Scheme S1- Syntheses of the pyrrolidinium salts

$N$-alkyl- $N$-methylpyrrolidinium bromides were prepared by dropwise addition of the $n$-alkyl bromide $(0.02 \mathrm{~mol})$ to a solution of $N$-methylpyrrolidine $(0.022 \mathrm{~mol})$ in ethyl acetate $(5 \mathrm{~mL})$ and stirring for $1 \mathrm{~d}$ at $50^{\circ} \mathrm{C}$. The white solid product was rinsed with cold ethyl acetate.

$N$-butyl- $N$-octylpyrrolidinium bromides were prepared by dropwise addition of $n$-bromooctane $(0.015 \mathrm{~mol})$ to a solution of $N$-octylpyrrolidine $(0.017 \mathrm{~mol})$ in ethyl acetate $(5 \mathrm{~mL})$ and stirring for $1 \mathrm{~d}$ at $50^{\circ} \mathrm{C}$. The white solid product was rinsed with cold ethyl acetate.

$\mathrm{N}, \mathrm{N}$-dialkylpyrrolidinium bromides were prepared by dropwise addition of the n-alkyl bromides $(0.03 \mathrm{~mol})$ to a solution of pyrrolidine $(0.01 \mathrm{~mol})$ in acetonitrile $(5$ 
$\mathrm{mL}) . \mathrm{K}_{2} \mathrm{CO}_{3}(0.012 \mathrm{~mol})$ was added as a solid-phase acid scavenger and the solution was stirred for 2 days at $60^{\circ} \mathrm{C}$. After filtration, the filtrant volume was decreased by rotary evaporation, and the white solid product precipitate formed after addition of ethyl acetate. The white solid products were rinsed with cold ethyl acetate.

Selected ${ }^{1} \mathrm{H}$ NMR data are provided below for each reaction category above.

$\operatorname{Py}_{1.8} \mathbf{B r} \delta_{\mathrm{H}}\left(400 \mathrm{MHz}, \mathrm{D}_{2} \mathrm{O}\right): 0.78-0.81\left(\mathrm{~m}, 3 \mathrm{H}, \mathrm{CH}_{3}\right), 1.21-1.29\left(\mathrm{~m}, 10 \mathrm{H}, \mathrm{CH}_{2}\right)$, 1.69-1.76 (m, 2H, $\mathrm{NCH}_{2} \mathrm{CH}_{2}$ ), 2.14 (m, 4H, H-pyrrolidinium), 2.96 (s, 3H, $\mathrm{NCH}_{3}$ ), 3.23-3.27 (m, 2H, $\mathrm{NCH}_{2}$ ), 3.40-3.43 (m, 4H, H-pyrrolidinium).

Py $_{4.8} \mathbf{B r} \delta_{\mathrm{H}}\left(400 \mathrm{MHz}, \mathrm{D}_{2} \mathrm{O}\right): 0.86-0.87$ (m, 3H, $\mathrm{CH}_{3}$-octyl), 0.88-0.90 (m, 3H, $\mathrm{CH}_{3}$-butyl), 1.21-1.35 (m, 12H, $\left.\mathrm{CH}_{2}\right), 1.59-1.67$ (m, 4H, $\left.\mathrm{NCH}_{2} \mathrm{CH}_{2}\right), 2.09$ (m, 4H, H-pyrrolidinium), 3.14-3.20 (m, 4H, $\mathrm{NCH}_{2}$ ), 3.40-3.44 (m, 4H, H-pyrrolidinium).

Py ${ }_{8.8} \mathbf{B r} \delta_{\mathrm{H}}\left(400 \mathrm{MHz}, \mathrm{D}_{2} \mathrm{O}\right): 0.81-0.84\left(\mathrm{~m}, 6 \mathrm{H}, \mathrm{CH}_{3}\right), 1.24-1.33$ (m, 20H, $\left.\mathrm{CH}_{2}\right), 1.65$ (m, 4H, $\mathrm{NCH}_{2} \mathrm{CH}_{2}$ ), 2.14 (m, 4H, H-pyrrolidinium), 3.21-3.25 (m, 4H, $\mathrm{NCH}_{2}$ ), 3.50 (m, 4H, H-pyrrolidinium).

\section{Section 2. Capillary zone electrophoresis (CZE)}

CZE is widely used for separation of solvated species by charge-to-mass ratios. Our group previously reported ${ }^{39}$ a technique for applying a constant electric field on an aqueous-phase buffer to generate a stable background signal at $210 \mathrm{~nm}$. Supernatant species passing through the detector, including Py, en and $\mathrm{Na}^{+}$, block the background signal and result in negative peaks; peak positions and areas are associated with 
species identity and concentration. Working standard solutions were prepared from $\mathrm{NaBr}, \mathrm{Py}_{4.8} \mathrm{Br}$ and en in a $15 \mathrm{mM}$ imidazole buffer $(\mathrm{pH}=5.2)$.

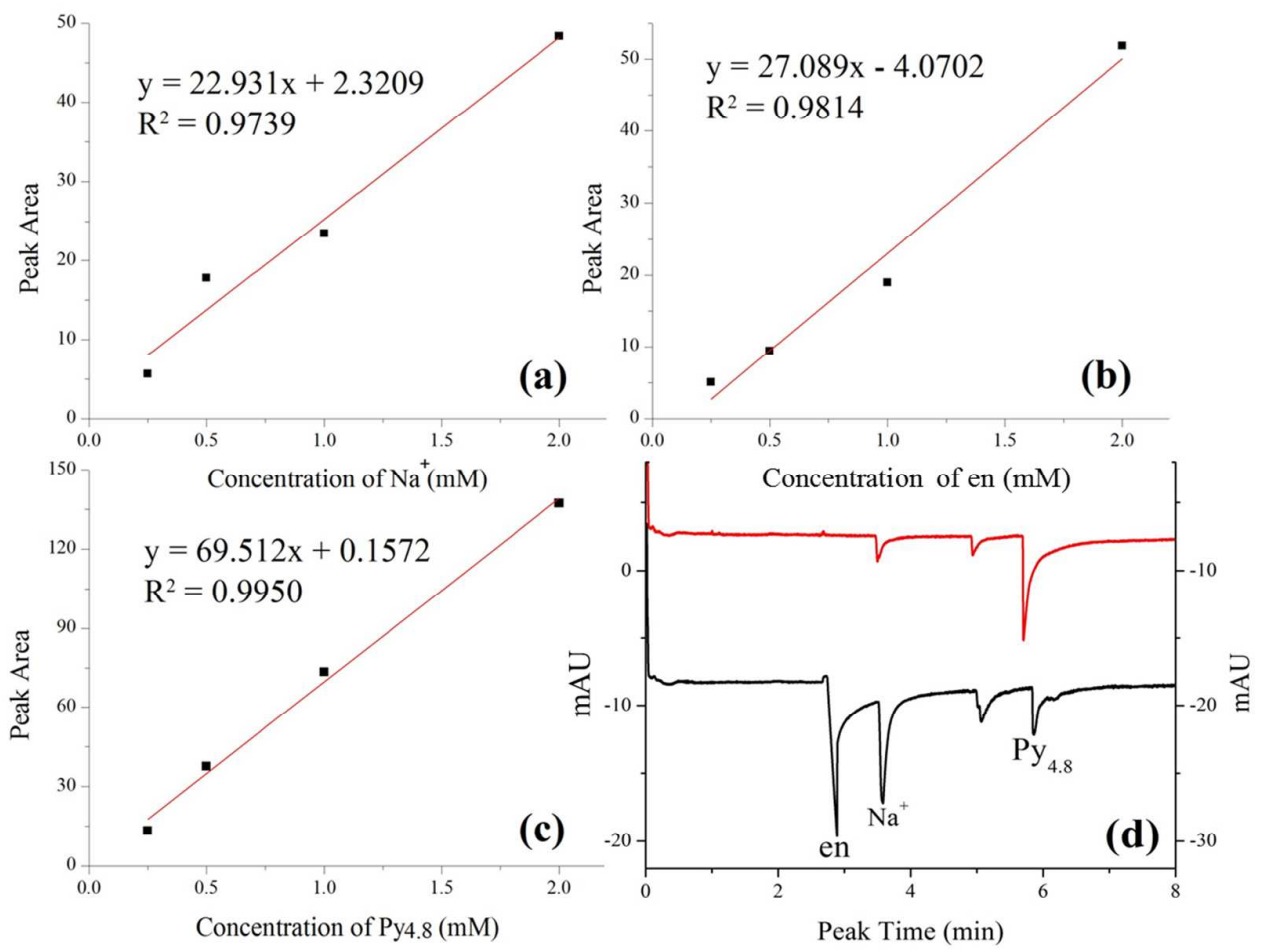

Figure S1. CZE standard calibration curves for (a) $\mathrm{Na}^{+}$(b) en and (c) $\mathrm{Py}_{4.8}$ and (d) observed negative peaks for reaction supernatant before (top) and after (bottom) exchange reaction of $\mathrm{Py}_{4.8}$ for $\mathrm{Na}(\mathrm{en})^{+}$.

\section{Section 3. Footprint Area Calculation}

Pyrrolidinium geometries were optimized using B3LYP method with a 6-31G* basis set on Gaussian 09W software, with alkyl chains constrained to a parallel plane conformation (Figure S2a). Molecular projections onto a planar surface (Figure S2b) were performed using a Monte Carlo method and Matlab r2015b software. Calculated 
footprint areas are provided in Table S1.
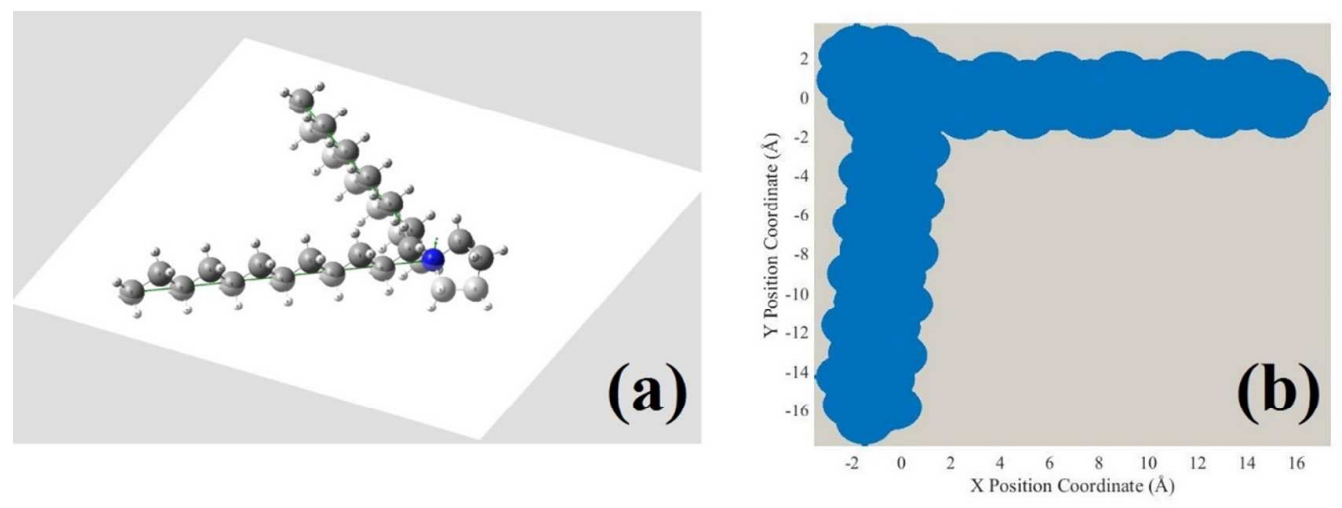

Figure S2. (a) The parallel trans-chain geometry and molecular projection of $\mathrm{Py}_{12.12}$, and (b) the calculated footprint area of the cation (blue).

\begin{tabular}{|c|c|c||c|c|c|}
\hline Cation & $\begin{array}{c}\text { Footprint Area } \\
/ \mathrm{nm}^{2}\end{array}$ & $\begin{array}{c}\text { vdW Volume } \\
/ \mathrm{nm}^{3}\end{array}$ & Cation & $\begin{array}{c}\text { Footprint Area } \\
/ \mathrm{nm}^{2}\end{array}$ & $\begin{array}{c}\text { vdW Volume } \\
/ \mathrm{nm}^{3}\end{array}$ \\
\hline $\mathrm{T} 1 \mathrm{~A}$ & 0.29 & 0.091 & $\mathrm{Py}_{8.8}$ & 1.09 & 0.354 \\
\hline $\mathrm{T} 2 \mathrm{~A}$ & 0.49 & 0.160 & $\mathrm{~T} 5 \mathrm{~A}$ & 1.07 & 0.367 \\
\hline $\mathrm{Py}_{1.4}$ & 0.52 & 0.164 & $18 \mathrm{~T} 1 \mathrm{~A}$ & 1.13 & 0.384 \\
\hline $\mathrm{Py}_{4.4}$ & 0.67 & 0.216 & $\mathrm{~T} 6 \mathrm{~A}$ & 1.27 & 0.436 \\
\hline $\mathrm{T} 3 \mathrm{~A}$ & 0.67 & 0.229 & $\mathrm{Py}_{1.18}$ & 1.46 & 0.406 \\
\hline $\mathrm{Py}_{1.8}$ & 0.75 & 0.233 & $\mathrm{~T} 7 \mathrm{~A}$ & 1.47 & 0.505 \\
\hline 12T1A & 0.82 & 0.280 & Py12.12 & 1.49 & 0.493 \\
\hline $\mathrm{T} 4 \mathrm{~A}$ & 0.87 & 0.298 & T8A & 1.69 & 0.574 \\
\hline $\mathrm{Py}_{4.8}$ & 0.88 & 0.285 & D18D1A & 1.99 & 0.678 \\
\hline
\end{tabular}

Table S1. Footprint areas and vdW volume for quaternary alkyl ammonium cation intercalates in GICs. 